AperTO - Archivio Istituzionale Open Access dell'Università di Torino

Unveiling the interaction between PDT active squaraines with ctDNA: A spectroscopic study

This is a pre print version of the following article:

Original Citation:

Availability:

This version is available http://hdl.handle.net/2318/1790927

since 2021-06-17T12:08:14Z

Published version:

DOI:10.1016/j.saa.2020.119224

Terms of use:

Open Access

Anyone can freely access the full text of works made available as "Open Access". Works made available under a Creative Commons license can be used according to the terms and conditions of said license. Use of all other works requires consent of the right holder (author or publisher) if not exempted from copyright protection by the applicable law. 


\section{Unveiling the interaction between PDT active squaraines with 2 ctDNA: a spectroscopic study}

4 Cosmin Butnarasu ${ }^{a}$, Nadia Barbero ${ }^{b}$ Guido Viscardi ${ }^{b}$ and Sonja Visentin ${ }^{a}$

a University of Torino, Department of Molecular Biotechnology and Health Science, Via Quarello15, 10135 Torino, Italy

${ }^{b}$ University of Torino, Department of Chemistry and NIS Interdepartmental Centre, Via Pietro Giuria 7, 10125 Torino, Italy

${ }^{*}$ Corresponding author: Sonja Visentin, sonja.visentin@unito.it

Keywords: DNA, squaraines, photodynamic therapy (PDT), interaction, groove binders

\section{ABSTRACT}

Squaraine dyes are potential photosensitizers in photodynamic therapy (PDT) due to their ability to release reactive oxygen species (ROS) and cause DNA damage. For this reason, the evaluation and determination of the type of interaction between squaraines and DNA is of the utmost importance.

In this study different spectroscopic techniques such as UV-Vis and fluorescence spectroscopies were used to investigate the type of interaction that occurs between two photosensitizers (halogenated squaraines, i.e. $\mathrm{Br}-\mathrm{C} 4$ and I-C4) and calf thymus DNA (ctDNA). Squaraines were found to bind ctDNA externally following a minor groove binding as they were able to replace Hoechst (a classic groove binder) from the groove of DNA. This binding mode was further supported by iodide quenching studies, ionic strength assay and Florescence Resonance Energy Transfer. Moreover, association $\left(\mathrm{K}_{\mathrm{A}}\right)$ and dissociation $\left(\mathrm{K}_{\mathrm{D}}\right)$ constants were obtained and compared with constants of well-known groove binders.

\section{Introduction}

The living organisms encloses all the genetic information useful for their development and functioning within deoxyribonucleic acid (DNA). As DNA is the key component for organisms well- 
well as many antiretroviral and antimicrobial agents [1]. Based on the mechanism of interaction with DNA, drugs are distinguished between groove-binders, intercalating, strand-breaking and covalent bonding [2]. Some of these drugs generates harmful reactive oxygen species (ROS) capable to produce DNA damage. Proteins, lipids and nucleic acids are the biological targets of ROS. The alteration induced by ROS usually produce disfunctions of normal activities of the biological targets and that brings eventually to cell death [3,4]. From a clinical point of view the generation of ROS in specific and defined target points in the human body are of utmost importance in photodynamic therapy (PDT). PDT encompasses the topical or systemically administration of a photosensitizer which, after irradiation at an appropriate wavelength, is capable of producing ROS, resulting in damage to target cancer cells in which it is selectively accumulated [3,5]. Recently our group synthesized and studied some series of polymethine dyes demonstrating their ability to release ROS [6,7]. It was shown that in particular two squaraines named $\mathrm{Br}-\mathrm{C} 4$ and I-C4 are potential photosensitizers for PDT (Figure 1) [6].

Squaraine dyes are the products of dicondensation reactions between electron-rich substrates and squaric acid. In the last two decades great interest was addressed to this class of organic dyes because of their interesting photochemical and photophysical characteristics. Indeed, squaraines display an intense absorption and emission in the red to near infrared region. These photophysical features raised their use in a huge amount of technologies, such as renewable energy [8-11], biological applications [6,12-15] and sensitizers for PDT [5,16,17]. Moreover, different studies have proved that while in dark conditions squaraines are hardly cytotoxic, after irradiation at proper wavelength, they induced a significative phototoxic activity in cancer cells, which was proportional to the squaraine concentration $[5,16]$.

Since small compounds can interact with the double strand of DNA in different ways, it is essential to decipher the mechanism of interaction at molecular level in order to design novel and promising drugs for clinical use. Intercalators and groove binders behave differently with the genetic material: the intercalators insert into the double helix, forming a stronger and more damaging bond with DNA than groove binders. The groove binders, on the other hand, remain on the outside of the double helix, bonding in a less powerful manner; anyway, this still causes DNA damage even if to a lesser extent. These differences on the binding with DNA allow us to discriminate the various bonds through the use of spectrophotometric techniques. Although several papers have been published concerning the photodynamic activity of halogenated squaraines and their damage to DNA $[6,16,18]$, little is known about their mechanism of interaction with DNA. For a better understanding of the mechanism of photobiological activity, in this study, we used several spectrophotometric techniques, like UV-Vis spectroscopy, fluorescence spectroscopy and FRET (Supporting Information), to determine how the squaraines bind to DNA. 


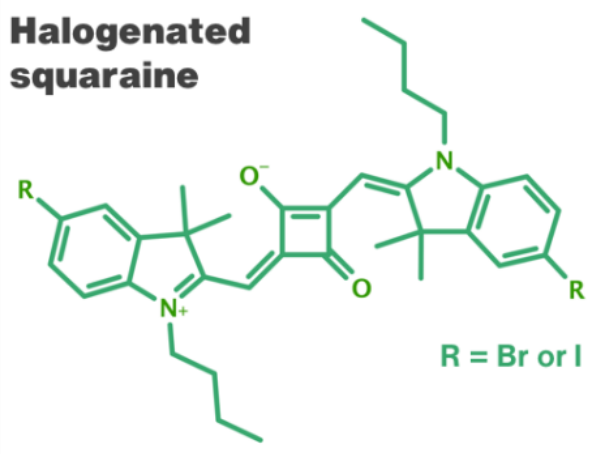

Fig. 1. Molecular structure of the two investigated squaraines.

\section{Materials and methods}

\subsection{Materials}

Ethidium bromide (EB), calf thymus DNA (ctDNA) and dimethyl sulfoxide (DMSO) were purchased from Merck and used without further purification. An in-house Millipore system was used to obtain Millipore grade water (resistivity: $18.2 \mathrm{M} \Omega \mathrm{cm}$ at $25{ }^{\circ} \mathrm{C}$ ). Squaraines were synthetized as previously reported [6]. TNE buffer was obtained using-Picofluor ${ }^{\mathrm{TM}}$ protocol. TNE buffer was prepared by dissolving $12.1 \mathrm{~g}$ of Tris, $3.7 \mathrm{~g}$ of EDTA and $116.9 \mathrm{~g}$ of $\mathrm{NaCl}$ in $1 \mathrm{~L}$ of water. The $\mathrm{pH}$ of TNE was adjusted to 7.4 with $\mathrm{HCl}$. All dilutions useful to the various analyses in this study were performed using this particular buffer that provides solutions to the correct ionic strength.

ctDNA stock solution was obtained by dissolving it in water under stirring and stored at $0-4{ }^{\circ} \mathrm{C}$ in the dark. The concentration of ctDNA stock solution was calculated by measuring the absorbance at $260 \mathrm{~nm}$ and using a molar absorption coefficient of $6600 \mathrm{~L} \mathrm{~mol}^{-1} \mathrm{~cm}^{-1}$. The purity of DNA solution was checked by calculating the absorbance ratio $A_{260} / A_{280}$. As the value of the ratio was between 1.8 and 1.9, thus meaning that ctDNA was satisfactorily free from protein, no further purification was required $[19,20]$. All the working solutions were further prepared by diluting the stock solution in buffer.

102 Squaraines stock solutions $(1 \mathrm{mM})$ were obtained by dissolving the solid in DMSO and dilutions for the experiments were made in TNE buffer. 


\subsection{Methods}

\subsubsection{UV-Vis measurements}

A UH5300 Hitachi spectrophotometer and a $1 \times 1 \mathrm{~cm}$ quartz cuvettes were used to record all the absorption measurements. The UV-Vis spectra of squaraines complexed with ctDNA were measured in the 200-700 nm range. Experiments were carried out by keeping a fixed amount of squaraines, $10 \mu \mathrm{M}$, in a total volume of $3 \mathrm{~mL}$ and subsequently titrated with increasing concentration $(0-77.4 \mu \mathrm{M})$ of ctDNA.

\subsubsection{Fluorescence measurements}

A Horiba Jobin Yvon Fluorolog 3 spectrofluorophotometer and a $1.0 \mathrm{~cm}$ quartz cells were used to record all the fluorescence spectra. The fluorescence of ctDNA-EB complex was obtained in the range $585-750 \mathrm{~nm}$ upon excitation at $286 \mathrm{~nm}$; slits were set on $5 \mathrm{~nm}$ and $3 \mathrm{~nm}$ for excitation and emission, respectively. ctDNA and EB concentrations to form the complex were set at 36.7 $\mu \mathrm{M}$ and $10 \mu \mathrm{M}$, respectively, in a volume of $3 \mathrm{~mL}$; squaraines concentration was varied from 0 $40 \mu \mathrm{M}$.

\subsubsection{Competitive displacement assays}

Hoechst 33258 (HOE) was added to a ctDNA solution in order to study the competitive displacement. The HOE-ctDNA complex containing $1 \mu \mathrm{M} \mathrm{HOE}$ and $10 \mu \mathrm{M}$ ctDNA was excited at $355 \mathrm{~nm}$. Emission spectra were recorded in the spectral range $375-600 \mathrm{~nm}$. Squaraine was gradually added $(0-200 \mu \mathrm{M})$ to a constant concentration of HOE-ctDNA complex. The cuvette was filled with TNE buffer to a final volume of $3 \mathrm{~mL}$.

\subsection{4. lodide quenching studies}

The iodide quenching tests were accomplished after exciting squaraines and recording the emission spectra in presence of gradually increased amounts of $\mathrm{KI}$, both in absence and presence of ctDNA $(50 \mu \mathrm{M})$. A total of $3 \mathrm{~mL}$ solution comprised $50 \mu \mathrm{M}$ squaraine, TNE buffer and variable concentration of $\mathrm{KI}$ in the range of 0-4 $\mathrm{mM}$. Fluorescence spectra were measured over the spectral range $280-500 \mathrm{~nm}$ upon excitation at $260 \mathrm{~nm}$. Fluorescence quenching efficiency both in absence and presence of ctDNA was analyzed using the Stern-Volmer equation.

\subsubsection{Role of ionic strength}

The effect of ionic strength was investigated by changing the concentration of sodium chloride $(\mathrm{NaCl})$ in the range of $0-90 \mathrm{mM}$, in a total volume of $3 \mathrm{~mL}$ containing $50 \mu \mathrm{M}$ squaraine, $50 \mu \mathrm{M}$ ctDNA and TNE buffer. Fluorescence spectra were recorded in the spectral range 280-500 nm and the excitation wavelength was set at $260 \mathrm{~nm}$. 


\section{Results and discussion}

144

A

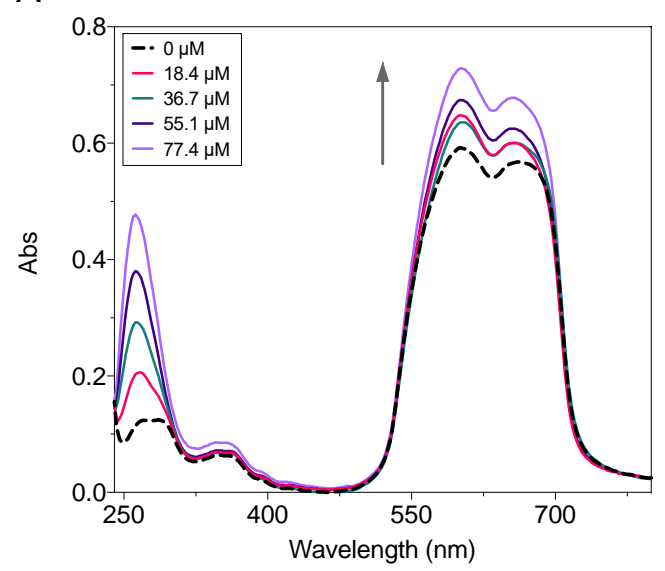

B

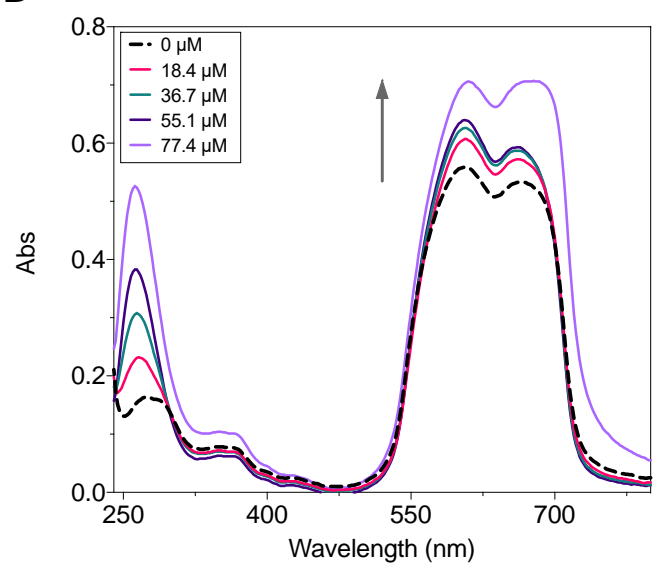

\subsection{UV-Vis absorption studies}

UV-Vis spectroscopy is one of the simplest and easily reproducible technique used to assess the type of interaction between macromolecules (usually proteins) and small molecules [21]. Through UV-Vis study the structure and the conformation of complexes can be explored. The absorption spectra of squaraines with and without ctDNA were registered and are displayed in Figure 2. Generally, the bound of small molecules to DNA via intercalation, involves the aromatic groups of the chromophore and the DNA base pairs, of whom mechanism of interaction is stackingbased. The resulting maximum of absorption will display bathochromism and a significant hypochromic effect. When intercalation takes place, the probability of electron transition and coupling energy are reduced, thus resulting in a color reduction and a red-shift phenomenon $[2,22,23]$. On the other hand, if electrostatic interaction occurs, mainly a hyperchromic effect will be observed as a consequence of the changes of the structure and conformation of DNA upon the formation of the complex between the compound and DNA. Generally speaking, when a positively charged compound bind to the negatively charged phosphate groups of DNA backbone, the secondary structure of DNA will shrink and spectroscopically a hyperchromic effect is usually observed [24,25]. Similarly, the groove binding interaction produces an enhancement of the absorption bands, which is proportional to the concentration of DNA[23]. As shown in Figure 2, with the addition of increasing concentration of ctDNA to a SQ dye solution, no bathochromic shifts or hypochromic effects were observed. Actually, upon increasing the concentration of DNA, we recorded an increase of the absorption bands at 596 and $660 \mathrm{~nm}$ corresponding to squaraines. These observations suggest that rather than an intercalative mode of interaction between squaraines and ctDNA, an electrostatic or groove binding mode is preferred. 
171 Figure 2. UV-Vis spectra of squaraines-ctDNA interaction. In the spectrum (A) it is represented 172 the interaction between ctDNA and $\mathrm{Br}-\mathrm{C} 4$ and in the spectrum (B) the interaction between ctDNA 173 and I-C4. The black dashed line represents the absorption spectrum of squaraine alone, while

174 the colored lines represent squaraine absorption spectrum at increasing concentrations of ctDNA.

\subsection{Fluorescence quenching mechanism of SQ-ctDNA-EB system}

178 Ethidium bromide (EB) is a planar molecule characterized by a very weak fluorescence in 179 aqueous medium. However, when it intercalates into the base pairs of DNA, it encounters a more 180 hydrophobic environment that forces the loss of any water molecule associated with EB. As water 181 is a very efficient fluorescence quencher the result is a great increase of fluorescence emission $182[19,26-28]$. With this in mind, a complex ctDNA-Ethidium Bromide (EB) was used because the emission spectrum of the ctDNA alone is too low in terms of intensity. The enhanced fluorescence intensity can be turned off by adding a second molecule and the amount of fluorescence quenching can be used to define the binding between the second compound and ctDNA[29]. Figure 3 shows the fluorescence spectra of ctDNA-EB complex upon the increasing concentrations of squaraines (SQ). The fluorescence of ctDNA-EB systems at $605 \mathrm{~nm}$ decreased as the amount of squaraines increased. The fluorescence quenching data of the complex SQctDNA-EB were analyzed by three different approaches in order to calculate the equilibrium association $\left(\mathrm{K}_{\mathrm{A}}\right)$ and dissociation $\left(\mathrm{K}_{\mathrm{D}}\right)$ constants. For the SQ-ctDNA-EB system, two possible reasons describe the reduction of the ctDNA-EB emission upon addition of $S Q$. The first reason consists in replacement of the intercalated EB from the double strand which decreases the concentration of EB binding to ctDNA. The second reason is the turn off the fluorescence of ctDNA-EB complex by bond of SQ [1]. The absorption measurements suggest that the binding mechanism between $S Q$ and ctDNA was not relying on intercalation but more likely on electrostatic or groove binding modes. Moreover, based on the values of binding constant reported in Table 1, we can state that the replacement of EB from ctDNA was not possible as the binding constant of EB-DNA is $5.16 \times 10^{5} \mathrm{~mol} \mathrm{~L}^{-1}$ as reported by Ramana et al. [19,26], while for the SQ-ctDNA-EB system, binding constant are on average 5 fold lower. To confirm this hypothesis further investigation were conducted.

201 

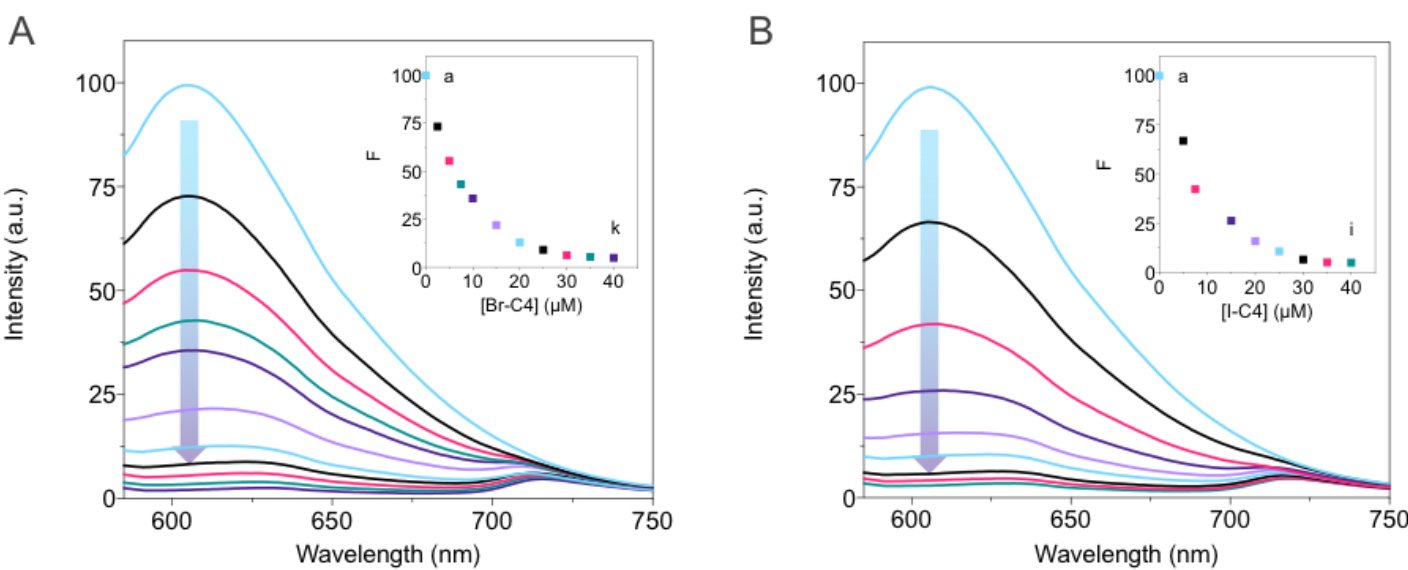

202

203

204

205

206

207

208

209

210

211

212

213

214

215

216

217

218

219

220

221

222

223

224

225

226

227

228

Figure 3. Fluorescence spectra of SQ-ctDNA-EB. (A) Interaction between ctDNA-EB and Br-C4 and $(B)$ interaction of ct-DNA-EB and I-C4. The most intensive light blue lines represent emission spectra of ctDNA-EB complex; all the other colored lines are the emission spectra of interactions between ctDNA-EB and squaraines. [Br-C4] $]_{-k}=0,2.5,5,7.5,10,15,20,25,30,35,40 \mu \mathrm{M}$; [l$\mathrm{C} 4]_{\mathrm{a}-\mathrm{i}}=0,5,7,5,15,20,25,30,35,40 \mu \mathrm{M}$. The insets represent the variation of the maximum of fluorescence upon increasing the concentration of squaraine.

\subsubsection{Stern-Volmer equation}

The fluorescence quenching data of SQ-ctDNA-EB complex were analyzed according to SternVolmer equation (Eq.1)

$$
\frac{\mathrm{F}_{0}}{\mathrm{~F}}=1+\mathrm{K}_{\mathrm{SV}}[\mathrm{Q}]
$$

where $F_{0}$ is the fluorescence intensity of ctDNA-EB alone and $F$ is the fluorescence intensity of the complex in presence of increased concentration of squaraine, Ksv is the Stern-Volmer quenching constant and $[\mathrm{Q}]$ is the squaraine concentration. Quenching data are presented as plots of $F_{0} / F$ versus [Q], yielding an intercept of one on the $y$-axis and a slope equal to $\mathrm{K}_{s v}$. The fluorescence quenching of ctDNA-EB upon binding to SQ shows positive deviation from the SternVolmer equation. This tendency is often observed when the extent of quenching is large. In such events, usually only the linear part of the plot is fitted to Stern-Volmer equation (insets on Figure $4 \mathrm{~A}$ and $4 \mathrm{~B}$ ), in order to gain information about the SQ-ctDNA-EB interaction constant [30].

\subsubsection{Non-linear least squares}

Data were fitted also according to a non-linear fit method, based on Equation 2:

$$
y=\frac{\left(B_{\max } \cdot[Q]\right)}{\left(K_{D}+[Q]\right)}
$$

where, $y$ is the explicit binding obtained by measuring fluorescence intensity, Bmax is the maximum extent of the complex SQ-ctDNA-EB created at saturation and $K_{D}$ is the equilibrium 
dissociation constant. Since in a biomolecular reaction at equilibrium the $\mathrm{K}_{\mathrm{D}}$ and $\mathrm{K}_{\mathrm{A}}$ are mutually correlated, we calculated $K_{A}$ as the reciprocal of $K_{D}$. The binding curves are displayed in Figure 4 ( $C$ and $D$ ); the percentage of bound ctDNA, that is, the ordinate axis, calculated from the emission maximum intensities, is plotted against the squaraines concentration. The $\mathrm{K}_{A}$ and $\mathrm{K}_{\mathrm{D}}$ values are reported in Table 1.

\subsubsection{Lineweaver-Burk}

236

Another frequently used method to linearize data is the Lineweaver-Burk equation based on

237 Equation 3:

$$
\frac{1}{\left(F_{0}-F\right)}=\frac{1}{F_{0}}+\frac{K_{D}}{F_{0} \cdot[Q]}
$$

In Figure 4 the reciprocals of $F_{0}-F$ are plotted against reciprocals of [Q]. $K_{D} / F_{0}$ ratio is the slope of the line while $\mathrm{F}_{0}$ is the reverse of the intercept. The equilibrium dissociation $\left(\mathrm{K}_{\mathrm{D}}\right)$ and association $\left(\mathrm{K}_{\mathrm{A}}\right)$ constants are thus easily calculated and are reported in Table 1.

242 As reported in Table 1, we can observe that constants obtained with different analysis methods perfectly agree to each other. Association constants are in the order of $10^{5} \mathrm{M}^{-1}$ which is appreciably lower than that of the intercalation binding mode. The $\mathrm{K}_{\mathrm{A}}$ of classic intercalators such as ruthenium complexes are reported to be around $10^{6} \mathrm{M}^{-1}[31,32]$, while even higher values on the order of $10^{7} \mathrm{M}^{-1}$ were reported for anthracycline as daunorubicin [33,34]. The value of the obtained binding constants is an indirect confirmation of the mode of interaction of squaraine with DNA.

Table 1. Association $\left(\mathrm{K}_{\mathrm{A}}\right)$ and Dissociation $\left(\mathrm{K}_{\mathrm{D}}\right)$ constants at $25{ }^{\circ} \mathrm{C}$ calculated with different mathematical models.

252

\begin{tabular}{llllll} 
& \multicolumn{2}{l}{ Stern-Volmer } & \multicolumn{2}{l}{ Non-Linear Fit } & \multicolumn{2}{l}{ Lineweaver-Burk } \\
\cline { 2 - 6 } & $\mathrm{K}_{\mathrm{sv}}$ & $\mathrm{K}_{\mathrm{D}}$ & $\mathrm{K}_{\mathrm{A}}$ & $\mathrm{K}_{\mathrm{D}}$ & $\mathrm{K}_{\mathrm{A}}$ \\
& $\left(\cdot 10^{5} \mathrm{M}^{-1}\right)$ & $\left(\cdot 10^{-6} \mathrm{M}\right)$ & $\left(\cdot 10^{5} \mathrm{M}^{-1}\right)$ & $\left(\cdot 10^{-6} \mathrm{M}\right)$ & $\left(\cdot 10^{5} \mathrm{M}^{-1}\right)$ \\
\hline Br-C4 & 2.10 & 8.40 & 1.19 & 8.92 & 1.12 \\
$\mathrm{I}-\mathrm{C4}$ & 2.09 & 7.39 & 1.35 & 8.38 & 1.19 \\
\hline
\end{tabular}


A

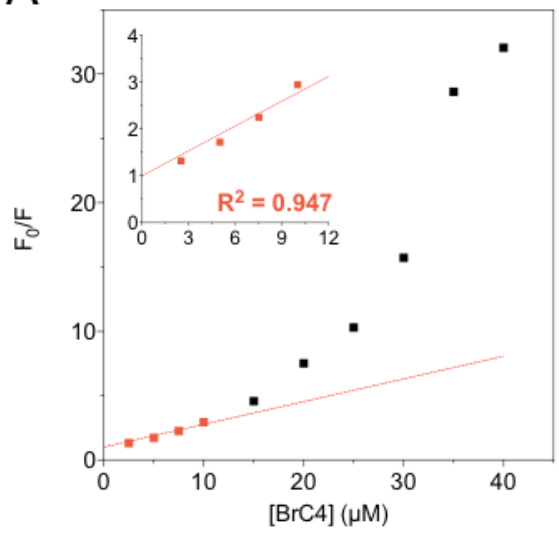

C

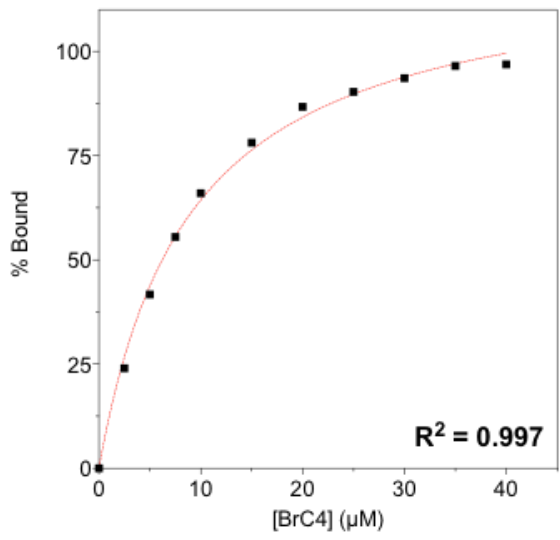

E

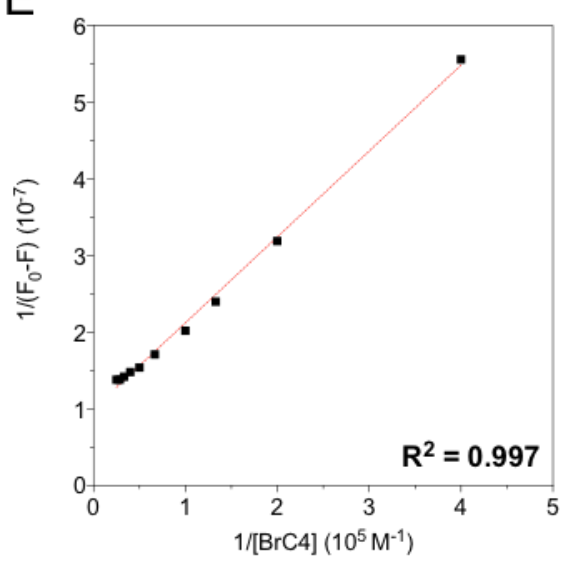

B

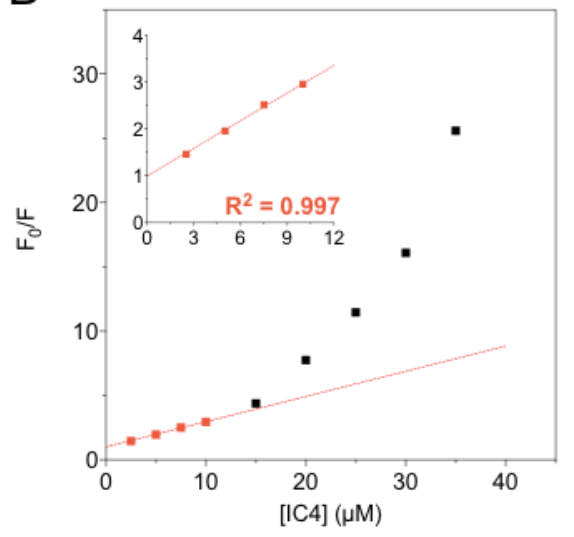

D

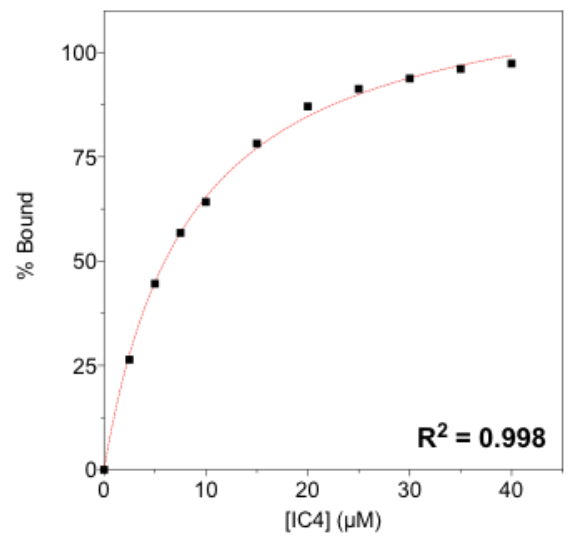

$\mathrm{F}$

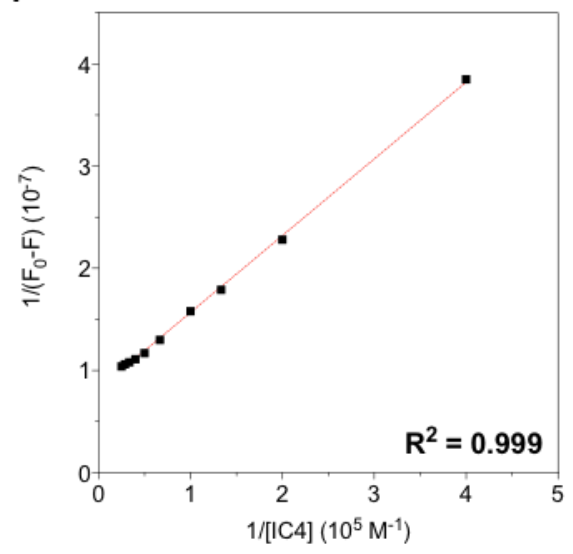

256 Figure 4. Data analysis of fluorescence quenching. In the spectra $(A)$ and $(B)$ are represented the Stern-Volmer analysis of BrC4-ctDNA-Eb and IC4-ctDNA-EB interactions, respectively. The insets on $(A)$ and $(B)$ reports the linear tract of the Stern-Volmer plot. In the spectra (C) and (D) are represented the non-linear least squares analysis of the same interactions. At last, in the spectra $(E)$ and $(F)$ are represented the Lineweaver-Burk analysis of the interactions. 


\subsection{Competitive Displacement Assay}

262

263

264

265

266

267

268

269

270

271

272

273

274

275

276

277

To better understand how squaraines bind DNA, we carried out competitive binding experiments. In this experiment, Hoechst 33258, a commonly used minor groove binder of DNA with high specificity for AT-rich sequences, was employed to study the competitive replacement by groove binders $[1,20,21]$. Hoechst 33258 has a very weak fluorescence intensity in aqueous solutions however, on binding with DNA, it shows an increase in the fluorescence intensity characterized by a strong band at $458 \mathrm{~nm}[26,35]$. Molecules that bind DNA via groove binding mode can replace Hoechst 33258 from the minor groove of DNA that resulting in quenching of fluorescence of the band at $458 \mathrm{~nm}$, which corresponds to the DNA-Hoechst system. As shown in Figure 5, upon addition of gradually increased squaraine concentration, the fluorescence intensity of HoechstctDNA complex was found to diminish. This spectroscopic response can be explained as squaraines gradually replaced the groove bounded dye from ctDNA. This result suggests that rather than intercalation, there is a high probability that the binding of squaraine to ctDNA involves the minor groove sites, as indeed proved by squaraine ability to displace Hochest. This hypothesis was further evaluated by performing iodide quenching experiment.

A

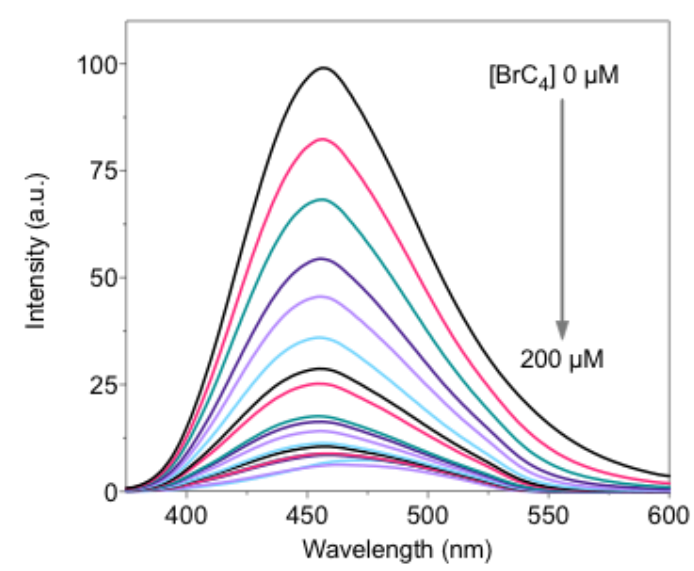

C

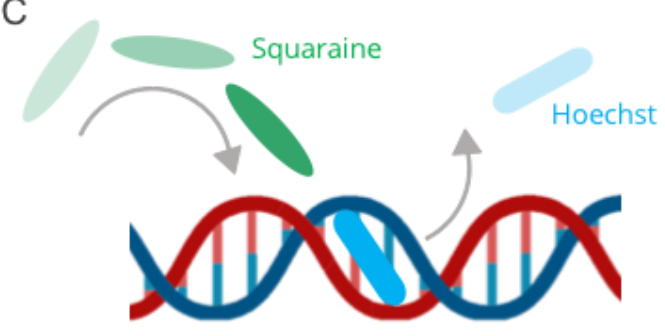

B

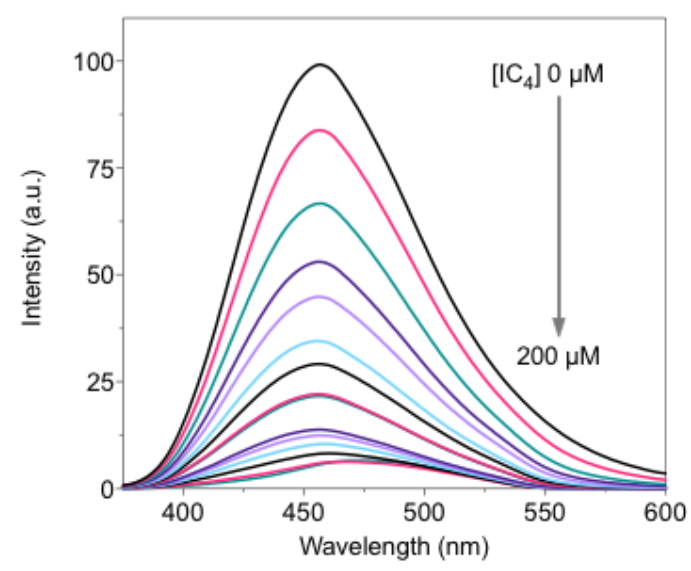

Minor groove occupied by squaraine

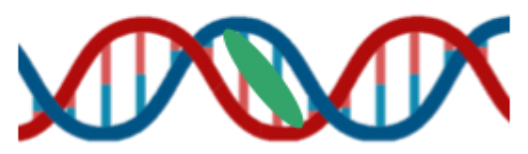

Figure 5. Fluorescent intensity of Hoechst-ctDNA in presence of increasing concentrations of $\mathrm{Br}$ C4 (A) and I-C4 (B). [Br-C4] $]_{\mathrm{a}-\mathrm{r}}=0,5,10,15,20,25,30,35,40,45,50,60,70,80,90,100,150$, 

representation of the displacement of Hoechst by squaraine on the minor groove (C).

\section{4 lodide Quenching Study}

lodide ion quenching experiments are useful on understanding if the location of the bonded molecules is placed either outside or inside of DNA helix. lodide ions are known to turn off the fluorescence of small compounds in aqueous environments. When DNA is present, the negative charges on the phosphate groups repeal the iodide ions. If a small compound intercalates the double strand of DNA, then it will be well protected, as the contact with negatively charged molecules (such as iodide ions) toward such compound will be restricted because of electrostatic repulsion. Though, molecules that bind DNA preferably by groove binding or electrostatic mechanism, meaning that these molecules are exposed to the surrounding environment, will be susceptible to the attack of quenchers present in the free medium even when DNA is present $[20,21]$. The level of accessibility of small compounds to negatively charged quenchers in the environment and in presence of ctDNA is described by Ksv that can be calculated using SternVolmer equation (see Eq. 1 and Figure 6). Reduction in the magnitude of Ksv in presence of DNA is achieved with intercalation, though for groove binders or electrostatic interaction, it remains mostly unaffected. In Figure 6, is reported that $\mathrm{KI}$ could efficiently quench the emission of squaraines. However, the presence of ctDNA, produce a slight increase of the Ksv value. The calculated $\mathrm{K}_{\mathrm{sv}}$ values in the absence and presence of ctDNA for $\mathrm{Br}-\mathrm{C} 4$ by $\mathrm{KI}$ was found to be 38 and $70 \mathrm{M}$ respectively, while for $\mathrm{I}-\mathrm{C} 4$ the $\mathrm{Ksv}$ values are 20 and $34 \mathrm{~mol} \mathrm{~L}^{-1}$ respectively. The magnitude of quenching of squaraines that we observe in the presence and in the absence of ctDNA is almost unchanged and therefore, there is a higher probability that the interaction of squaraines with DNA take place outside the DNA helix. Taking together the competitive displacement assay and the iodide quenching study, we can state with more confidence that the binding of squaraines to ctDNA is mainly guided by groove binding interaction. 
A

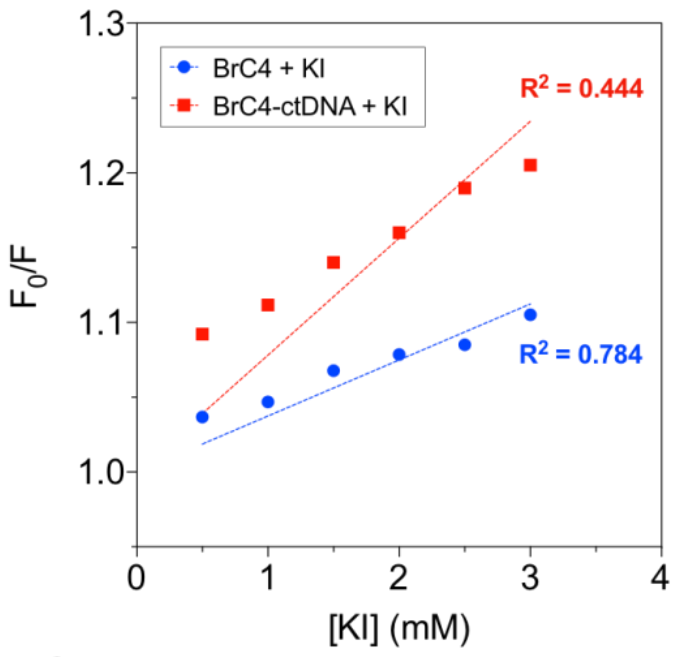

C

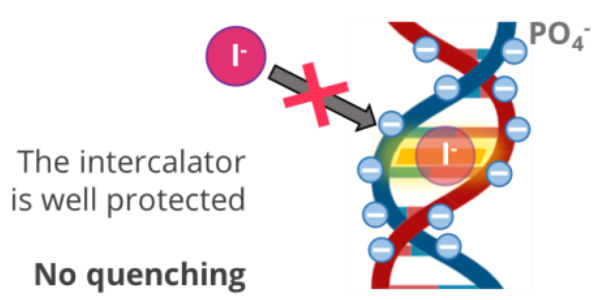

B

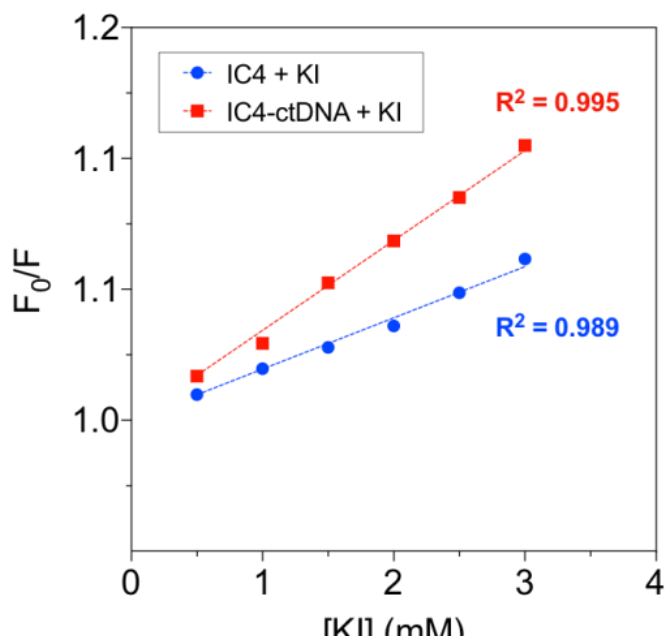

[KI] (mM)

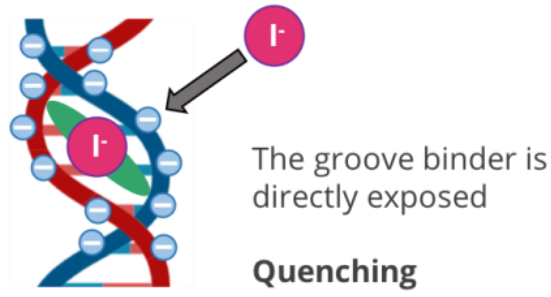

Figure 6. Stern-Volmer plots for fluorescence quenching of $\mathrm{Br}-\mathrm{C} 4(\mathrm{~A})$ and $\mathrm{I}-\mathrm{C} 4(\mathrm{~B})$ by $\mathrm{KI}$ in the absence and presence of ctDNA $(50 \mu \mathrm{M})$. Concentrations of $\mathrm{KI}$ was varied from 0.5 to $3 \mathrm{mM}$. Schematic representation of the mechanism of quenching of fluorescence of the groove binders by action of iodide $(C)$. While intercalators are well protected by being inserted between nucleotides, groove binders are directly exposed to the surrounding environment.

\subsection{Effect of lonic Strength}

Another methodology used to discriminate the binding between small compounds and ctDNA is the investigation of ionic strength on the system. Normally, strong electrolyte as sodium chloride $(\mathrm{NaCl})$ is used for this assay. After solubilization, $\mathrm{Na}^{+}$partially neutralizes the anionic helix of DNA so reducing the electrostatic repulsion between DNA strands. Small molecules that intercalate into the adjacent base pairs of DNA will be shielded from the surrounding solvent and so the emission intensity will be almost unvaried with the increasing of the concentration of $\mathrm{NaCl}$ [36]. In case of surface binding molecules, particularly for electrostatic-dependent binding, the bound with DNA takes place outside the groove; in this case $\mathrm{NaCl}$ will reduce the interaction which will be translated in the reduction of emission intensity. Nonetheless, for groove binding molecules, with the increasing of the concentration of $\mathrm{NaCl}$ a proportional decrease of fluorescence intensity is usually observed. The increased ionic strength shrinks and deepens the DNA grooves. The 
induced structure modification of the helix cause the release of the grove bonded molecule and that translates in the decrease of fluorescence intensity $[11,37]$. So, the effect of $\mathrm{NaCl}$ on the fluorescence of ctDNA-squaraine were studied. The experimental results indicate that the fluorescence intensities of ctDNA-squaraine was decreased with increasing of $\mathrm{NaCl}$ concentration (Figure 7). These results can further confirm that the interaction between ctDNA and squaraines is groove binding related.

336

A

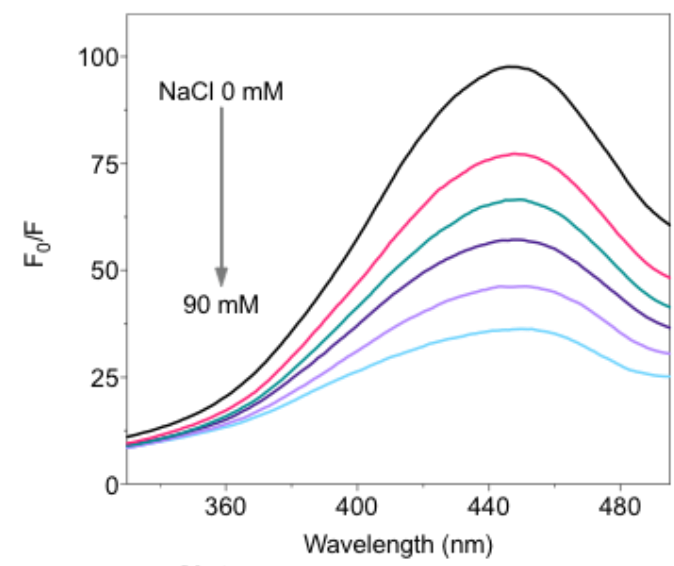

C

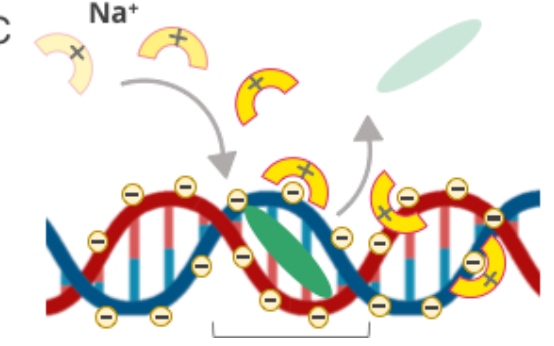

B
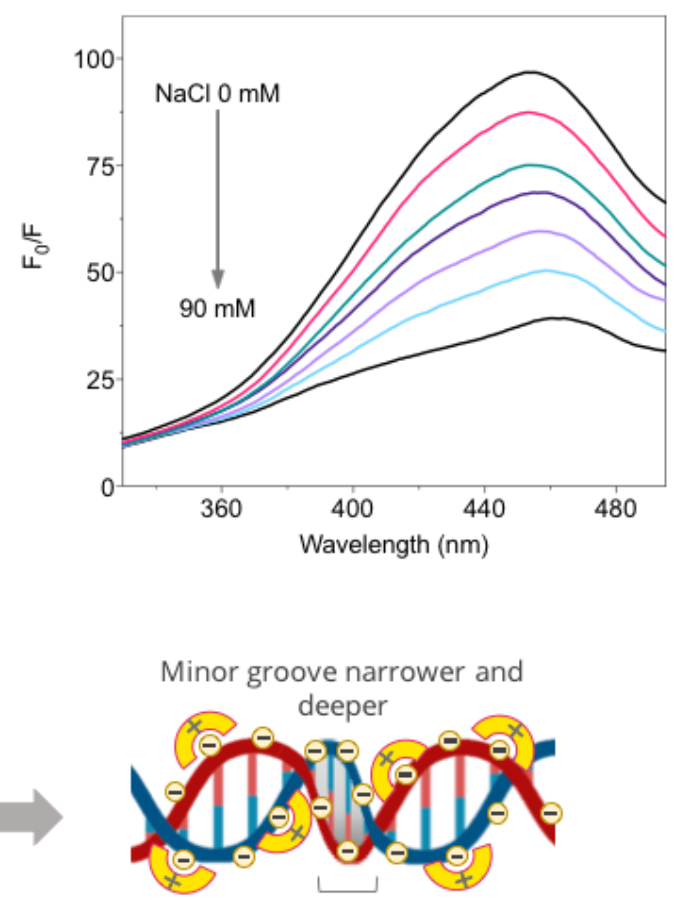

Figure 7. Effects of ionic strength on the fluorescence intensity of Br-C4-ctDNA (A) and I-C4ctDNA (B). Schematic representation of the ionic strength on the structure of DNA and the implication of squaraine accommodation into the minor groove $(C)$.

\section{Conclusions}

In this study the interaction between ctDNA and $\mathrm{Br}$ - and I-C4 squaraines has been studied through different spectroscopic techniques. Based on the data collected by absorption and emission spectroscopies, displacement assay, iodide quenching study, ionic strength effect and FRET (Supporting Information) data, we can state that the binding mode of squaraine with DNA was disclosed as minor groove binding. The squaraines have a $\mathrm{K}_{\mathrm{A}}$ order of $10^{5} \mathrm{M}^{-1}$. Considering that the order of magnitude of association constant of groove binders is usually known to be around $10^{3} \mathrm{M}^{-1}[38,39]$, we conclude that $\mathrm{Br}$ - and I-C4 have quite a high affinity for ctDNA. This work is 
expected to provide deeper insight into understanding the mechanism of interaction of squaraines with DNA and the knowledge gained from this study could be used for the development of potential probes for DNA as well as more selective and efficient photodynamic therapy agents.

\section{Declaration of competing interests}

The authors declare that they have no known competing financial interests or personal relationships that could have appeared to influence the work reported in this paper.

\section{Acknowledgments}

The authors acknowledge the financial support from the University of Torino (Ricerca Locale ex60\%, Bando 2019) and from the Fondazione Cassa di Risparmio (CRT) di Torino, Italy.

\section{References}

[1] M.M.V. Ramana, R. Betkar, A. Nimkar, P. Ranade, B. Mundhe, S. Pardeshi, In vitro DNA binding studies of antiretroviral drug nelfinavir using ethidium bromide as fluorescence probe, J. Photochem. Photobiol. B Biol. 151 (2015) 194-200. https://doi.org/10.1016/j.jphotobiol.2015.08.012.

[2] K. Nakamoto, M. Tsuboi, G.D. Strahan, Drug-DNA Interactions: Structures and Spectra, Wiley, 2008.

[3] A.M. Rkein, D.M. Ozog, Photodynamic Therapy, Dermatol. Clin. 32 (2014) 415-425. https://doi.org/10.1016/j.det.2014.03.009.

[4] H. Abrahamse, M.R. Hamblin, New photosensitizers for photodynamic therapy, Biochem. J. 473 (2016) 347-364. https://doi.org/10.1042/BJ20150942.

[5] R.R. Avirah, D.T. Jayaram, N. Adarsh, D. Ramaiah, Squaraine dyes in PDT: from basic design to in vivo demonstration, Org. Biomol. Chem. 10 (2012) 911-920. https://doi.org/10.1039/C1OB06588B.

[6] L. Serpe, S. Ellena, N. Barbero, F. Foglietta, F. Prandini, M.P. Gallo, R. Levi, C. Barolo, R. Canaparo, S. Visentin, Squaraines bearing halogenated moieties as anticancer photosensitizers: Synthesis, characterization and biological evaluation, Eur. J. Med. Chem. 113 (2016) 187-197. https://doi.org/10.1016/j.ejmech.2016.02.035.

[7] B. Ciubini, S. Visentin, L. Serpe, R. Canaparo, A. Fin, N. Barbero, Design and synthesis of symmetrical pentamethine cyanine dyes as NIR photosensitizers for PDT, Dye. 
Pigment. 160 (2019) 806-813. https://doi.org/10.1016/j.dyepig.2018.09.009.

J. Park, N. Barbero, J. Yoon, E. Dell'Orto, S. Galliano, R. Borrelli, J.H. Yum, D. Di Censo, M. Grätzel, M.K. Nazeeruddin, C. Barolo, G. Viscardi, Panchromatic symmetrical squaraines: A step forward in the molecular engineering of low cost blue-greenish sensitizers for dye-sensitized solar cells, Phys. Chem. Chem. Phys. 16 (2014) 24173-

[10] D. Saccone, S. Galliano, N. Barbero, P. Quagliotto, G. Viscardi, C. Barolo, Polymethine

[11] S. Kashanian, S. Javanmardi, A. Chitsazan, M. Paknejad, K. Omidfar, Fluorometric study of fluoxetine DNA binding, J. Photochem. Photobiol. B Biol. 113 (2012) 1-6.

[9] J. Park, C. Barolo, F. Sauvage, N. Barbero, C. Benzi, P. Quagliotto, S. Coluccia, D. Di Censo, M. Grätzel, M.K. Nazeeruddin, G. Viscardi, Symmetric vs. asymmetric squaraines as photosensitisers in mesoscopic injection solar cells: A structure-property relationship study, Chem. Commun. 48 (2012) 2782-2784. https://doi.org/10.1039/c2cc17187b. https://doi.org/10.1016/j.jphotobiol.2012.04.002.

[12] N. Barbero, C. Butnarasu, S. Visentin, C. Barolo, Squaraine Dyes: Interaction with Bovine Serum Albumin to Investigate Supramolecular Adducts with Aggregation-Induced Emission (AIE) Properties, Chem. - An Asian J. 14 (2019) 896-903.

[13] M. Shimi, V. Sankar, M.K.A. Rahim, P.R. Nitha, S. Das, K. V. Radhakrishnan, K.G. https://doi.org/10.1002/asia.201900055. Raghu, Novel glycoconjugated squaraine dyes for selective optical imaging of cancer cells, Chem. Commun. 53 (2017) 5433-5436. https://doi.org/10.1039/c6cc10282d.

[15] G. Alberto, N. Barbero, C. Divieto, E. Rebba, M.P. Sassi, G. Viscardi, G. Martra, Solid silica nanoparticles as carriers of fluorescent squaraine dyes in aqueous media: Toward a molecular engineering approach, Colloids Surfaces A Physicochem. Eng. Asp. 568 (2019) 123-130. https://doi.org/10.1016/j.colsurfa.2019.01.052. Photodynamic Therapy: Study of Their Cytotoxicity and Genotoxicity in Bacteria and Mammalian Cells, Photochem. Photobiol. 76 (2002) 672-677. https://doi.org/10.1562/0031-8655(2002)0760672SDFPTS2.0.CO2.

I] I. Miletto, A. Fraccarollo, N. Barbero, C. Barolo, M. Cossi, L. Marchese, E. Gianotti, Mesoporous silica nanoparticles incorporating squaraine-based photosensitizers: a
}

D. Ramaiah, I. Eckert, K.T. Arun, L. Weidenfeller, B. Epe, Squaraine Dyes for 
combined experimental and computational approach, Dalt. Trans. 47 (2018) 3038-3046. https://doi.org/10.1039/C7DT03735J.

[18] D. Ramaiah, I. Eckert, K.T. Arun, L. Weidenfeller, B. Epe, Squaraine Dyes for Photodynamic Therapy: Mechanism of Cytotoxicity and DNA Damage Induced by Halogenated Squaraine Dyes Plus Light (>600 nm), Photochem. Photobiol. 79 (2004) 99. https://doi.org/10.1562/0031-8655(2004)79<99:sdfptm>2.0.co;2.

[19] Y. Cui, E. Hao, G. Hui, W. Guo, F. Cui, Investigations on the interactions of diclofenac sodium with HSA and ctDNA using molecular modeling and multispectroscopic methods, Spectrochim. Acta Part A Mol. Biomol. Spectrosc. 110 (2013) 92-99. https://doi.org/10.1016/J.SAA.2013.01.093.

[20] S.U. Rehman, T. Sarwar, H.M. Ishqi, M.A. Husain, Z. Hasan, M. Tabish, Deciphering the interactions between chlorambucil and calf thymus DNA: A multi-spectroscopic and molecular docking study, Arch. Biochem. Biophys. 566 (2015) 7-14. https://doi.org/10.1016/j.abb.2014.12.013.

[21] M.A. Husain, T. Sarwar, S.U. Rehman, H.M. Ishqi, M. Tabish, Ibuprofen causes photocleavage through ROS generation and intercalates with DNA: a combined biophysical and molecular docking approach, Phys. Chem. Chem. Phys. 17 (2015) 13837-50. https://doi.org/10.1039/c5cp00272a.

[22] R. Arif, P.S. Nayab, Akrema, M. Abid, U. Yadava, Rahisuddin, Investigation of DNA binding and molecular docking propensity of phthalimide derivatives: in vitro antibacterial and antioxidant assay, J. Anal. Sci. Technol. 10 (2019) 1-9. https://doi.org/10.1186/s40543-019-0177-1.

[23] Y. Yang, J.Y. Bian, Y.H. Li, H.C. Guan, Y.R. Tang, Y.L. Chen, S.M. Yue, Construction of six complexes from 2-(2-pyridyl)benzothiazole and polycarboxylic acids: Synthesis, crystal structures and DNA-binding properties, J. Mol. Struct. (2020). https://doi.org/10.1016/j.molstruc.2019.127219.

[24] F. Arjmand, A. Jamsheera, DNA binding studies of new valine derived chiral complexes of tin(IV) and zirconium(IV), Spectrochim. Acta - Part A Mol. Biomol. Spectrosc. (2011). https://doi.org/10.1016/j.saa.2010.06.009.

[25] M. Sirajuddin, S. Ali, A. Badshah, Drug-DNA interactions and their study by UV-Visible, fluorescence spectroscopies and cyclic voltametry, J. Photochem. Photobiol. B Biol. 124 (2013) 1-19. https://doi.org/10.1016/J.JPHOTOBIOL.2013.03.013.

[26] M.M.V. Ramana, R. Betkar, A. Nimkar, P. Ranade, B. Mundhe, S. Pardeshi, Synthesis of a novel $4 \mathrm{H}$-pyran analog as minor groove binder to DNA using ethidium bromide as fluorescence probe, Spectrochim. Acta - Part A Mol. Biomol. Spectrosc. 152 (2016) 165171. https://doi.org/10.1016/j.saa.2015.07.037.

[27] R. Gaur, M. Usman, A combined experimental and theoretical investigation of ruthenium(II)-hydrazone complex with DNA: Spectroscopic, nuclease activity, 
topoisomerase inhibition and molecular docking, Spectrochim. Acta Part A Mol. Biomol. Spectrosc. 209 (2019) 100-108. https://doi.org/10.1016/J.SAA.2018.10.035.

[28] J. Olmsted, D.R. Kearns, Mechanism of Ethidium Bromide Fluorescence Enhancement on Binding to Nucleic Acids, Biochemistry. 16 (1977) 3647-3654.

[29] M.M. Aleksić, V. Kapetanović, An overview of the optical and electrochemical methods for detection of DNA - Drug interactions, Acta Chim. Slov. 61 (2014) 555-573.

[30] M. Airoldi, G. Barone, G. Gennaro, A.M. Giuliani, M. Giustini, Interaction of doxorubicin with polynucleotides. a spectroscopic study, Biochemistry. 53 (2014) 2197-2207. https://doi.org/10.1021/bi401687v.

[31] S. Mardanya, S. Karmakar, D. Maity, S. Baitalik, Ruthenium(II) and osmium(II) mixed chelates based on pyrenyl-pyridylimidazole and 2,2'-bipyridine ligands as efficient DNA intercalators and anion sensors, Inorg. Chem. 54 (2015) 513-526. https://doi.org/10.1021/ic502271k.

[32] E. Wachter, D. Moyá, S. Parkin, E.C. Glazer, Ruthenium Complex "Light Switches" that are Selective for Different G-Quadruplex Structures, Chem. - A Eur. J. 22 (2016) 550559. https://doi.org/10.1002/chem.201503203.

[33] Y. Lu, J. Lv, G. Zhang, G. Wang, Q. Liu, Interaction of an anthracycline disaccharide with ctDNA: Investigation by spectroscopic technique and modeling studies, Spectrochim. Acta - Part A Mol. Biomol. Spectrosc. 75 (2010) 1511-1515. https://doi.org/10.1016/j.saa.2010.02.008.

[34] A.A. Almaqwashi, T. Paramanathan, I. Rouzina, M.C. Williams, Mechanisms of small molecule-DNA interactions probed by single-molecule force spectroscopy, Nucleic Acids Res. 44 (2016) 3971-3988. https://doi.org/10.1093/nar/gkw237.

[35] J.H. Shi, J. Chen, J. Wang, Y.Y. Zhu, Binding interaction between sorafenib and calf thymus DNA: Spectroscopic methodology, viscosity measurement and molecular docking, Spectrochim. Acta - Part A Mol. Biomol. Spectrosc. (2015). https://doi.org/10.1016/j.saa.2014.09.056.

[36] N. Akbay, Z. Seferoğlu, E. Gök, Fluorescence interaction and determination of calf thymus DNA with two ethidium derivatives, J. Fluoresc. 19 (2009) 1045-1051. https://doi.org/10.1007/s10895-009-0504-9.

[37] S. Bi, T. Zhao, Y. Wang, H. Zhou, B. Pang, T. Gu, Binding studies of terbutaline sulfate to calf thymus DNA using multispectroscopic and molecular docking techniques, Spectrochim. Acta - Part A Mol. Biomol. Spectrosc. (2015). https://doi.org/10.1016/j.saa.2015.06.042.

[38] D. Sahoo, P. Bhattacharya, S. Chakravorti, Quest for mode of binding of 2-(4(dimethylamino)styryl)-1-methylpyridinium iodide with calf thymus DNA, J. Phys. Chem. B. 114 (2010) 2044-2050. https://doi.org/10.1021/jp910766q.

[39] B. Jana, S. Senapati, D. Ghosh, D. Bose, N. Chattopadhyay, Spectroscopic exploration 

with flavonoids having additional hydroxyl groups, J. Phys. Chem. B. 116 (2012) 639645. https://doi.org/10.1021/jp2094824.

507 